\title{
The Interpretation of Implicature: A Comparative Study between Implicature in Linguistics and Journalism
}

\author{
Dr. Mustafa Shazali Mustafa \\ Nile Valley University, P. O. Box 1843, Khartoum, Sudan \\ E-mail: mustafashazali65@gmail.com
}

\begin{abstract}
This study explores implicature as a pragmatic inference in some journalist texts. Content analysis has proved the existence of the inference in all types of news reporting. The study also reveals that implicature as a vital pragmatic element in the process of communication which bridges the gap between what is literally said and what is intentionally meant. Analysis of implicature has proved its importance to discourse analysis theories and the new English syllabi since it caters for what is said and what is understood in the process of communication. Sentence linguistics which has been used in school-classes since 1850 has been challenged by this pragmatic inference. That is, traditional grammar concentrated mainly on the structures of sentences and their internal systems. Implicature, however, employs the whole situation and it uses all the circumstances surrounding the utterance in order to really conceive the intended meaning of the producer of that utterance. Implicature as well plays a vital role in media language by bridging the gap between the different cultures. The paper shows this inference as a tool of cultural transfer and how far it can be harnessed as interdisciplinary system to illustrate linguistic pragmatic theory as well as explaining how media language works.
\end{abstract}

Index Terms - implicature, inference, and interdisciplinary

\section{INTRODUCTION.}

Unlike many other topics in pragmatics, implicature does not have an extended history in western culture. Many significant studies have been conducted on implicature. Ideas and views in implicature were f,irstly proposed by Grice $^{1}$ (1967). The most important studies are Cole and Morgan $1975^{2}$ and Oh and Dinned $1979^{3}$ because they drew the attention to the difference between what is said and what is intended. That is, the most efficient way for communication or learning a language for the last 150 years is responding to the signals by which the language conveys its structural meanings (Fries,1951: P.274) ${ }^{4}$. He also adds that many schools still devote a tremendous amount of time to this type of grammar and usage. Levinson $(1983)^{5}$ states that the notion of implicature provides some explicit account of how it is possible to mean more than what is literally expressed in the conventional sense of the linguistic expression uttered. For example the sentence 'It is hot' can have various pragmatic meanings. It may have the meaning that the speaker wants the listener to open the window for a fresh air. Levinson asserts this phenomenon of saying and understanding by saying the gap between what is literally said and what is conveyed is so substantial that we cannot expect a semantic theory to provide more than a small part of an account of how we communicate using language. The notion of implicature he thinks promises to bridge the gap. Modern linguistic theories link the notion of illocutionary acts and the politics and ideology of language. Yeh $(2002: 16)^{6}$ mentions that when expressing proposions in discourse, we are performing illocutionary acts. That is, to enable a reader to make sense of a discourse by inferring the covert propositional constructions from the interpretation of illocutionary act. Thore (2006) $)^{7}$ defines the notions of inference, presupposing, premises and implicature as notions of what sort of information texts carry between the lines. Thore (ibid) ${ }^{8}$ shows how inferred information contributes to the constitution of the author's ethos. He also shows what distinguishes language politics in Norway is that the way of speaking of the average Norwegian has a higher status than does spoken language in most other countries. Veronica (2006) ${ }^{9}$ displays the differences between English and Spanish in technical advertising texts in relation to the concepts of implicature and explicature by stating that both languages grade imlicature on scale which ranges from implicit (veiled) to explicit (open) implicatures. He also argues that discourse as text in context implies considering pragmatic choices that help build mental worlds. This notion of mental

\footnotetext{
${ }^{1}$ Grice,H.P. Logic and Conversation

${ }^{2}$ Cole,P. and Morgan,J.L.Syntax and Semantics3: Speech Acts

${ }^{3}$ Oh,C.K.and Dinneen,D.A.Syntax and Semantics11:Presupposition

${ }^{4}$ Fries,C.The Structure ofEnglish

${ }^{5}$ Levinson, S. Pragmatics

${ }^{6}$ Yeh,C. Language and Linguistics.Vol(3).No2

${ }^{7}$ Thore,R.Nordicom Review27.PP.!85-204

${ }^{8}$ Thore,R.Nordicom Review27.PP.!85-204

9 Veronica.Vivuno.Online Journal ofLanguage studies
} 
worlds may, however, be used to capture the customer's attention in marketing environment since it tries to surprise the potential reader or client (Cook, 1992) ${ }^{1}$. Chen and Yuan ${ }^{2}$ (2009) how that news discourse plays a key role in the construction of social reality .In their paper, they attempt to make a contrastive study of identity expressions used in Chinese news headlines( in journal issued in English ) from the perspective of social psychological pragmatics . They (ibid)rrived at that the use of headlines reflects the change in socio-psychological state of the Chinese society across different period of time. So one of the aims of the present paper is to show how this pragmatic inference of implicature may foreground the social identity of those who participate in news event in order to direct and attract readers, setting the agenda of the news. The classical literature is deemed be of necessity to understand the historical developments of linguistic features of semantics and pragmatics and how those two fields are always overlapped. That is, semantics theory alone can not provide adequate answers to linguistic phenomena such as ambiguity, metaphor, irony, euphemism, ellipsis and rhetorical questions. What semantics provides (see Yule, 2006,P.100) ${ }^{3}$ is just conceptual and associative meanings ignoring altogether what lies between the lines. Lexical semantics which may include the study of synonymy,antonymy, hyponymy, prototypes, homophones, homonyms, polysemy and collocation is now glossed through pragmatic perspectives ( inferences of deixis, speech acts, presupposion and implicature).

Grice (1967) ${ }^{4}$ discusses two kind of implicature. The first is conversational implicature which arises when the producer of an utterance violates one of his four maxims. These four maxims are the quantity maxim (do not provide more or less information than is required for the current purpose of exchange); the quality maxim (speak the truth); the relation maxim (be relevant); and the manner maxim (be clear). The second type is conventional implicature which arises from the conventional meanings of words and the discourse they occur in. Grice provides the example "She was poor but she was honest," which implicates some contrast between poverty and honesty. He argues that the word "but" has the same truth - conditional content as the word "and" with an additional conventional implicature to the effect that there is some contrast between the conjuncts. If someone deviates from the natural flow of these maxims or the Cooperative Principle (CP) as Grice names it , s/he will be implicating for other meanings. Pratt $\left(1966\right.$, P. 159 ) ${ }^{5}$ argues that implicature has been used a great deal by writers of literature and also by politicians, press agents, advertisers and other speakers interested in multiple meanings.

Multiple meaning or deviation from the normal flow of the CP can be seen in contrastive studies whose main concern is the appropriateness of the translatability of items such as lexical synonyms, common English particles, rhetorical questions, honorifics, metaphor, irony and euphemism. The above items contain implicature since all of them violate the CP mentioned earlier. For example there are some bilingual dictionaries and religious texts whose precision and right translations depend upon the implicature items of lexical synonyms and intertextuality. For example in the holy Quran the Arabic word which has the equivalent of the English word 'wife' has a dual usage. That is, in most Quran texts, Quran uses the word 'his wife' to indicate harmonious relationship, and Quran also uses the word "his woman" to implicate for disagreement between wife and husband. Most Quran translations have not delivered the right translation of that. Thousand of Arabic and English lexical synonyms need this inference of implicature to obtain the real intended meanings of the producer of utterances and texts whether they are spoken or written .

The speech act theory also has to do with Grice's maxims. Searle (1969) ${ }^{6}$ built upon the work of Austin (1962) ${ }^{7}$ to promote the notion of speech acts. Those acts are the elocutionary act, which is the act of making an utterance ,and the illocutionary force indicating device is the act performed or intended by the one who utters the locution. The effect of the utterance on the hearer/reader is considered as the per locution. There are some linguists like Searle $(1969){ }^{8}$,and Pratt (1989) ${ }^{9}$ who extend the speech act classification by adding acts of representatives (telling, insisting, stating); vindictive (assessing, evaluating, estimating, etc.) Searle also adds acts like directives (ordering, requesting, daring); comissives (promising, vowing, pledging, etc.) and declaratives (blessing, baptizing, dismissing, etc.).

\section{MEthodology}

Searching this pragmatic inference of implicature in a set of categories collected from the material of journalism in the form of new stories, articles is considered as an ultimate end of this paper. The articles have randomly been chosen from different cosmopolite channels. Cosmopolite is that situation in which the sender and receiver of an utterance belong to different social systems or sub-systems (Watson\& Hills $1984, \mathrm{P} 52)^{10}$. That is articles selected for this analysis have been taken from foreign journals and not local Sudanese who write in English language to guarantee the accuracy of writing. Considering different social systems , both the producer of an utterance and a decoder of it should mutually share the knowledge of the sent message. This shared knowledge help both of

\footnotetext{
1 Cook.G.The Discourse of advertising

2 Chen,Yenren. and Yuan,Zhoumin.Identity Expression in Chinese News Headlines

3 Yule,Geoge.The Study of Language

${ }^{4}$ Grice H.P. Logic and Conversation

${ }^{5}$ Pratt,M.Toward aSpeech Act Theory of Literary Discourse

${ }^{6}$ Searle ,j. R.A Speech Acts

${ }^{7}$ Austin J.L.How To Do Things with Words

8 Searle J. R.A Speech Acts

${ }^{9}$ Pratt, ,M.Toward aSpeech Act Theory of Literary Discourse

${ }^{10}$ Watson,J and Hill, A. . A dictionary of Communication and media studies
} 
them to understand the intended meaning of a particular message. This paper is endeavoring to study this inference of implicature as a means of cultural transfer. That is the issue of meaning has a recondite dimension which makes it as an inaccessible end if for example the writer of this paper approaches it quantitatively. This of course does not devalue the importance of statistics and the numerical researches that serve the purpose of reducing complex data to manageable and understandable proportions. In our case the problem was tackled qualitatively because in our discourses much is left unsaid, however, it is understood. Communication processes always involve the notion of intention and agency (Levinson 1983, P. 15) ${ }^{1}$. The description of the ability used by the hearers to interpret a discourse written or spoken is what is meant by pragmatics. That is , the notion of' 'intention and agency' described by Levinson(ibid) is glossed in this study as a pragmatic style that helps different ideologies and entities to mutually understand each other as a human beings. This may also lead to that implicature is a universal linguistic phenomenon found in all languages of the world . All the different identities of the world can have the same understanding from reading or hearing English new stories. That is, something original in their languages helps them build this innate capacity to share the intention of the producers of these English texts. So, if this inference of implicature is proved to be existed in the journalistic English texts chosen for this study, this will lead us to assume its universal existence in all living languages of the world we live in . This may also give potential insights for syllabus designers to include this inference in what is called communicative syllabi. The description of this ability to understand what is intended from what is said involves using certain mechanisms to interpret a particular discourse. Those mechanisms can be described as inferences of pragmatics. This paper, then , is an attempt to capture the meaning of one of them (implicature) through detailed description of some texts taken from journalism. Other pragmatic inferences like ironies, metaphors, deixis, presupposing and the morphological aspect of honorifics which have not found enough illustration in the movement of the generative semantics (1969-1970) are left for further studies.

Having linguistically been acknowledged with this pragmatic inference, the reader of this paper can easily discover it in the language of media in general and journalism in particular. This inference has been investigated in (Home and Foreign news, Human interest stories, Advertisements, Headlines) to see if it can cause variations in the styles of writing to media or not. That is to test if one variable (implicature) is understood by non native speakers of English Language or not ( a dependent variable). Questioning time order and causality of these two variables, the writer of this paper has randomly selected different excerpts to be used in the study without carefully thinking about the process of selection. This has intensively been conducted to consider future potential anticipatory effects which may cause a threat to the paper's internal validity. The study and to a far extent has controlled the threats of the internal validity by adopting a qualitative content analysis strategy ( textual analysis) which gives no room for extraneous events to coincide in time with the manipulation of the independent variable ( implicature) since what has been chosen is a kind of documentary journalistic texts taken randomly from different cosmopolite channels.

\section{IMPLICATURE IN JOURNALISTIC WRITING}

News writing is usually colored. Colored stories are a technical term, which refers "to any report that describes the flavor and excitement that go with large crowds” (River, 1964, P. 167) ${ }^{2}$. Therefore, most of the newspaper's political views are considered as "variant approximations, based on the author's subjective evaluations” (Duff \& Swindler, 1984

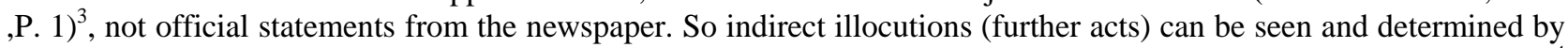
political realities and the goals of particular societies. Those political realities are expressed by Mueller, (1973 P. 101$)^{4}$ )$^{4}$ as a countries' ideology. An example of this is the following extract.

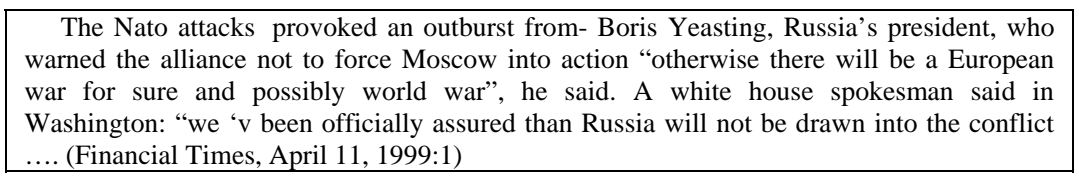

President Yeltsin in the above article is warning the alliance not to force his country into action. However, the White House's locution "We have been officially assured that Russia will not be drawn into the conflict", has an indirect illocution, hoping that or requesting that Russia should not interfere in this conflict of ethnic cleansing in Kosovo. Here it is to note that using a direct speech act to people whose culture is more accommodated to indirectness of request is considered as impolite. Whenever saying something that lessens the possible threat to another's face is called a face saving act (see Yule, 1997, P. 134) ${ }^{5}$. It is to note that speech acts should be explored within the theory of speech event, which caters to the enormous variations in what people say and do under different circumstances. This variation such as setting, topic and culture specifications should be looked at in the speech event theory. News stories then can be considered as one of the speech event types of our discussions.

\footnotetext{
${ }^{1}$ Levinson S. Pragmatics

Rivers,W, The Mass Media Reporting

Duff, B.and Shindler,R.Language and Style in Press

${ }^{4}$ Mueller, c . The Politics of Communication. A Study in the Political Sociology, Language socialization, and Legtimation

${ }^{5}$ Yule ,Geoge.The Study of Language
} 


\section{A. Speech Acts and Advertisements:}

Searle's (1969) ${ }^{1}$ mechanism of illocutionary indicating force device shows what the addressee is meant to do with a particular proposition that is expressed. Hence, it can be claimed that most assertive propositions of advertisements in journalism and media are meant to make the addressees believe in the advertised item. An example of this is foreign and colonial management's advertisement, which runs as follows

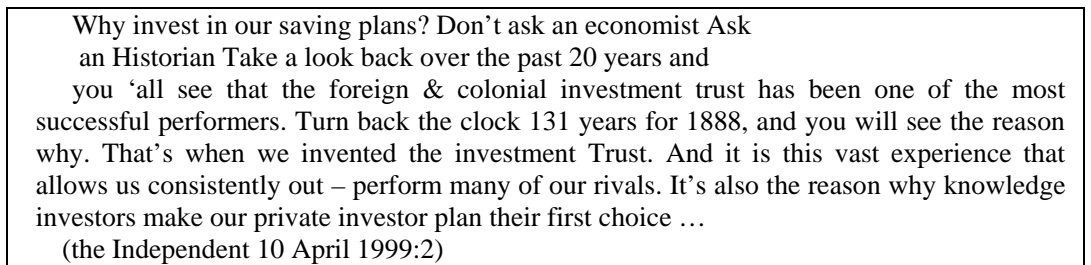

Each proposition in the above advertisement is shown in the table below with the possible meanings it conveys. These possible meanings are considered as inferences of speech acts, that is indirect illocutionary acts.

TABLE 1

SPEECH ACTS AND ADVERTISEMENTS

\begin{tabular}{|c|c|}
\hline Proposition & $\begin{array}{l}\text { Indirect illocution } \\
\text { acts }\end{array}$ \\
\hline $\begin{array}{l}1 \backslash \text { why invest in our saving plan? } \\
\text { Don’t ask an economist Ask an- Historian }\end{array}$ & Challenge \\
\hline $\begin{array}{l}2 \backslash \text { take a look back over the past } 20 \text { years and you 'all see that the foreign \& colonial investment trust has been } \\
\text { one of the most successful performers. }\end{array}$ & praising \\
\hline 3\Turn back the clock 131 years to 1888, and you will see the reason why & Praising \\
\hline $\begin{array}{l}\backslash \text { that's when we invented the investment Trust. And it is this vast experience that allows us consistently out - } \\
\text { perform many of our rivals. }\end{array}$ & Promising \\
\hline 5\It’s also the reason why knowledge investors make our private investor plan their first choice... & Promising \\
\hline
\end{tabular}

The same proposition might be inferred negatively in other kinds of discourses that is, it might not be conceived as a praising act. For example, imagine that an individual is devaluating his friend's ancestors by describing them with greed and selfishness, which the friend inherited from his grandfather by saying the following:

Turn back the clock 131 years to 1888, and you will see the reason why.

It is to note that this mutual knowledge of the 'grandfather' is deemed an important element in pragmatic theory. That is, both friends have prior assumptions and knowledge of the selfishness and greed of the grandfather.

B. 'Request', 'Advice', 'Question' and 'Advertisement':

According to Searle (1969, P. $66-7)^{2}$ the propositional content of 'request' and 'advice' is a future act that the speaker believes the hearer will be benefited from, and that the hearer is able to do. Moreover, it is not guaranteed for both the speaker and the hearer that the latter will do it in the normal course of event. Searle further adds that "advising is telling you what the best is for you." Thus, this future act of 'request' and 'advice' can be clearly viewed in journalistic and media advertisements. Below is an example of an advertisement which contains Searle's acts of 'question', 'advice', and 'request' of an illocutionary type.

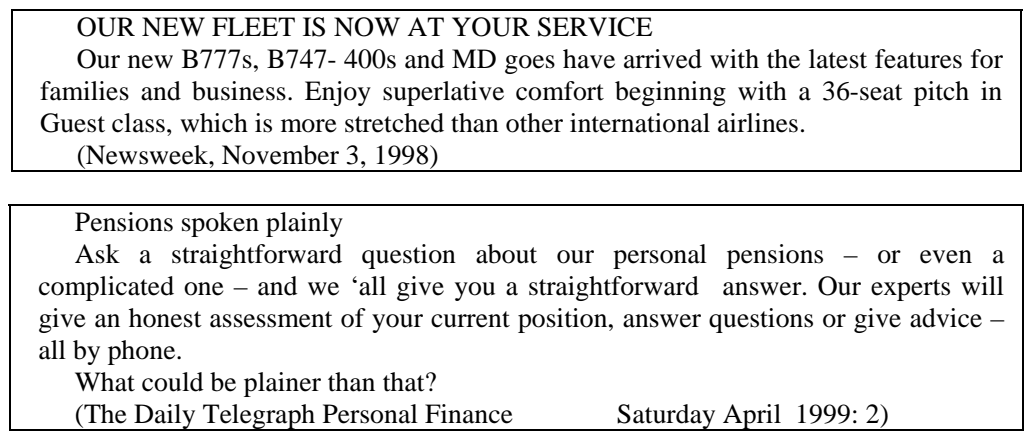

\footnotetext{
${ }^{1}$ Searle J. R.A Speech Acts

${ }^{2}$ Searle J. R.A Speech Acts. PP. 66-67
} 
TABLE 2

SEARLE'S ILLOCUTIONARY ACT AND ADVERTISEMENT

\begin{tabular}{|c|c|}
\hline Advertisements' Propositions & Searle’s Illocutionary Act \\
\hline $\begin{array}{l}1 \backslash \text { do you want the FREEDOM to choose your own doctor and hospital anywhere in the world? } \\
\text {... }\end{array}$ & $\begin{array}{l}\text { Exam question - speaker wants to } \\
\text { know if hearers know. }\end{array}$ \\
\hline $\begin{array}{l}\text { 2\ our new B 777s, B747 - 400s and MD go have arrived with the latest features for families and } \\
\text { business. Enjoy superlative comfort beginning with a } 36 \text { seat pitch in Guest Class, which is more } \\
\text { stretched than other international airlines. }\end{array}$ & $\begin{array}{l}\text { 'Advice' } \\
\text { It is a future act that the speaker } \\
\text { believes the hearer will be benefited } \\
\text { from. 'Advising is telling you what } \\
\text { the best is for you'. }\end{array}$ \\
\hline $\begin{array}{l}\text { 3\ Ask a straightforward question about our personal pension- or even a complicated one- and } \\
\text { we 'all give you a straightforward answer ... }\end{array}$ & $\begin{array}{l}\text { 'Request' } \\
\text { It is a future act that the speaker } \\
\text { believes will benefit the hearer }\end{array}$ \\
\hline
\end{tabular}

Yet, Searle (1969) ${ }^{1}$ divides question illocutionary act into two types of questions. The first kind of question is real questions in which the speaker wants to know the answer. The second type of question is the exam question in which the speaker wants to know if the hearer knows. It can therefore be assumed that most questions within advertisements are of Searle's second type.

What is more is that 'advice' and 'request' acts have been given the same propositional content, but we see that 'advising' someone is suggesting to the reader what is best for him/her. Unlike the 'request' act, which mainly depends upon a reasonable justifications to be provided for someone to make you believe in what is said, written and in our case, advertised.

Eventually, what makes advertisement attractive is expressed by Weirus' (1990, P. 48) ${ }^{2}$ article, which shows their range of colors, universal appeal, and their layout. Weirus in the same article also indicates that advertisements may contain idioms, proverbs and may exploit the imperative mood. An example of this is as follows:

Let's celebrate!

Discover the world's most satisfying Cigarette!

The above advertisement (Table 2) shows the imperative mood in phrases like 'Ask straightforward', 'Enjoy superlative comfort'. What is paradoxical here is that this very imperative mood is considered impolite in the language of politeness and requests. In politeness language, indirect commands and requests are preferable. Therefore, you cannot use the above phrase 'Ask straightforward' in politeness language unless you use it as an indirect speech act. you can, then, say it as follows:

Can you ask straightforward what you exactly want?

\section{Thank (for) \& Congratulate: Human Interest Stories:}

Human stories are always about individuals and their lives and events that are unlikely to affect many people. It has been observed that the type of illocutionary acts which prevail in such stories is 'Thank for' whose propositional content is a past act which has been done by the hearer. The speaker in the other way feels grateful or appreciative for this act (Searle 1969, P. 66) ${ }^{3}$. In addition, the second type of illocutionary act, which is commonly used in human stories, is 'congratulating' which is its propositional content shows events, act related to the hearer. The speaker here is pleased with this event (ibid. 66). The following examples are taken from the ' $\mathrm{Y} T$ Club' page in the daily telegraph.

It is worth mentioning that these acts, as identified by Searle, lie within the border of constitutive rules which are usually expressed as ' $\mathrm{Y}$ ' counts as $\mathrm{X}$ in context $\mathrm{C}$. In addition, human stories are highly individualistic and concern individuals and their lives and events that are unlikely to affect many people. Examples are as follows:

Example 1:

Tree - Top Sketch
Big thanks to Lauren Red Path (9) for this terrific picture of Tommy Toucan.
Lauren's recovering from a series of operations and Y T team all hope you get well
soon. Have a Y T Ticker for your artistic talents.
(The Daily Telegraph, No 443 April 3, 1999; 15)

Example 2:

$$
\begin{aligned}
& \text { Happy birthday to Hannah Rather who will be (8) tomorrow Hope you have a } \\
& \text { ovely day! Love from Mummy, Daddy, Ben Toby Bill. (The Daily Telegraph, 1999.) }
\end{aligned}
$$

Although Lauren's portrait in the “Tree Top Sketch” was appeared on April 3, 1999, its first proposition content indicated that this portrait had been drawn before that date. The YT team thanks Lauren for her terrific picture, which had been drawn in the past. Thus Searle's act of thanks (for) as an act which has been done by the hearer in the past is confirmed here.

The second story's proposition shows events of a birthday of Hanna Rothery, and the good wishes of the paper and

\footnotetext{
${ }^{1}$ Searle J. R.A Speech Acts

2 Weirs,A.Advertisement inClassroom

${ }^{3}$ Searle J. R.A Speech Acts
} 
Hanna's parents toward this occasion. Here, the propositional content of 'congratulate' is considered as an expression of pleasure towards this event .

\section{State Assert (that), Affirm and, Writing News Values:}

One of the main concerns of any newspaper is to persuade the intended readers to buy copies. Readers will obviously buy the paper if they like what is in it. The reporter will therefore use special vocabulary, that is to say words used in everyday English, but used in a particular way formal, descriptive or emotional. Headlines are also written according to particular criteria in order to shock the attention of the readers, and then hold his/her attention to read the paper again. News stories usually prepare the readers for the attitudes of the reporter or the newspaper legal body. They indicate the Illocutionary Force Indicating Device, which is defined by Searle (1969 P. 66) ${ }^{1}$ as 'a set of rules extracted from a set of conditions', or what the sufficient conditions under which one is said to have correctly uttered his sentences .

Therefore, the attitudes of the newspaper or the reporter towards the article can be considered as the intended meaning of the speaker. In addition, it is worth mentioning that two different newspapers can tackle the same incident with different styles of presentation. The examples below show that the same incident has been formally introduced in the first article and conversationally introduced in the second example:

Example 1:

Tourists Die in Cable - Car Plunge
SINGAPORE: A floating oil ring struck two cable- cars over Singapore harbor
on Saturday, throwing seven tourists to their deaths and trapping 13 others in cars
swinging 100 feet above the water.
(Duff\& Shindler, 1984: 25)

Example 2:

Jokes in the Cable Car Trap
SINGAPORE
The 13 survivors of the Singapore cable car tragedy told jokes to keep from
panicking as they waited all night to be rescued, it was revealed yesterday.
(ibid. :25)

From the above articles it can be said that 'reporting the news' is a process which includes acts of 'assert', 'state that', and 'affirm'. Therefore, the reporters in the above articles are simply stating their propositions, and not attempting to convince you to do something else. Normally, in stating their propositions reporters use language, which is as neutral as possible and unemotional language. Therefore, in any kind of formal writing the writer never uses the first person singular or plural. Exceptions are made here for opinion columns or some reviews where instead the passive voice is used. Furthermore, reporters use the present tense to create the effective impacts on his/her readers (River 1964 P. 50). ${ }^{2}$

Whenever a writer chooses emotional rather than neutral language, s/he is expressing an attitude so his/her writing may eventually be considered as subjective comments rather than objective reporting (Duff \& Shindler 1984, P. 33) ${ }^{3}$. However, both styles of writing lie within Searle's $(1969)^{4}$ border of 'assert' 'state (that)', and 'affirm' types of illocutionary acts. So, political, economic, social writing in media and journalism can be conceived to lie within the range of 'affirm', 'state that', and 'assert'. The exception is advertisements, which are usually conveyed through other illocutionary acts as is shown in the aforementioned examples. Below are two other examples, which assert this claim.

Example 1:

Press Curb
ZIMBABWE'S Government information department confirmed yesterday that
foreign journalists would be required to inform the Government of any trips beyond
25 miles of the capital and the second largest city, Bulawayo - AP.
(Duff \& Shindler, 1984: 11)

Example 2:

Sugar Pay Deal
The British Sugar Corporation is to give 2.500 of its workers a 9.5 percent pay
increase despite a breakdown of talks with trade union leaders. Half the workforce had
already accepted the offer, which will now be imposed on other employees.
(ibid: 11 )

The propositional contents of the above articles can be assumed as 'affirm', 'state (that)', and 'assert' of illocutionary acts types. The first article states that in Zimbabwe there are restrictions to foreign journalists' movements. While the second article is asserting a 9.5 percent pay increase to workers of the British Sugar

\footnotetext{
${ }^{1}$ Searle J. R.A Speech Acts. P.66

${ }^{2}$ Rivers W, The Mass Media Reportin

${ }^{3}$ Duff, B. and Shindler. R.Language and style in Press

${ }^{4}$ Searle, J. R. A Speech Acts
} 
Corporation. To emphasize these points table (3) shows a proposition from previous advertisement compared with the first articles proposition in order to gloss their indirect illocution or acts.

TABLE 3

INDIRECT ACTS OF ADVERTISEMENT \& NEWS WRITING

\begin{tabular}{|l|c|}
\hline Propositions & Indirect Acts \\
\hline $\begin{array}{l}1 \backslash \text { Advertisement } \\
\text { enjoy superlative comfort beginning with a } 36 \text { seat pitch in Guest class, which is more stretch than } \\
\text { other international airlines. }\end{array}$ & 'advice’ \& 'request' \\
\hline 2\Zimbabwe's Government Information department confirmed yesterday that foreign journalist .... & $\begin{array}{c}\text { 'affirm, 'state (that)' 'as- } \\
\text { sert' }\end{array}$ \\
\hline
\end{tabular}

How likely does the proposition content of the advertisement have indirect act of 'advice' request' and the news writing proposition has the act of 'assert', 'state (that)', 'affirm'? The writer attempts to convince you that the advertised item is something precious and good for you to attain or do. News writing propositions which reporters mainly aim at, stating particular incidents without attempting to convince you.

\section{E. 'Manner' and 'Quality' Implicature Maxims and Writing Headlines and Articles:}

As has been shown earlier, that implicature inference can be searched around in co-operative proposition that the sentence may convey. Normally, then in co-operative circumstances if one asserts something, s/he may implicate that $\mathrm{s} /$ he believes in it. In addition, if one asks a question /s/he may implicate that one desires an answer. Similarly, if one promises to do something one sincerely intends to do it and so on. Thus, any other use of such utterances as Levinson (1983, P. 118) ${ }^{1}$ shows is likely to be a 'spurious or counterfeit' one, and violates the maxim of quality. Therefore, as been negotiated, most types of writing in journalism may be taken to implicate for something by flouting Grice’s maxim of quality. Levinson's (ibid, P. 10) example here illustrates their notion of violating such a maxim.

- Queen Victoria was made of iron.

When one utters such a sentence, one can be assumed either non-co-operative, or intending to convey something different. Therefore, the appropriate interpretation is that Queen Victoria had properties of iron like hardness, resilience, non-flexibility, or durability. Therefore, interpretations as such can be taken positively as well as negatively and this depends on the context of its utterance. In journalism and media language, this maxim of quality can be conceived in the conflicts between different ideologies.

Implicature can also be derived, or observed in headlines. This can be undertaken by exploiting Grice's maxim of manner. This maxim urges the speaker on being brief and orderly, besides s/he is avoiding an obscurity of expressions.

In headlines, this maxim of 'manner' is usually violated, because headlines largely depend on shocking their readers. In order to shock readers, headlines writers tend to write them in an ambiguous way. Beyond the reason, why headlines always shock their readers lie a philosophy which aims at creating the motivation inside readers to buy the paper and to see what its article is about. So readers should develop a 'pragmatic nose' to interpret the newspaper's news values. For example, on November 9, 1998, Newsweek carried out a story whose headline is read as a 'New Threat', which caused ambiguity and disorder in the mentality of its readers. This state of ambiguity may lead the reader to relieve himself by reading the paper to know what kind of threat and to whom. When reading the paper, the first sentences (the leads) of the article provide the required information. Information that the article releases is that 'Saddam Hussein the President of Iraq defies the Security Council decision by suspending co-operation with the U N without really guaranteeing when economic sanctions would be lifted.

In addition, the Gricean maxim of quality that instructs the speaker's utterances to be true by not saying what is false (palmer, 1981: 173) ${ }^{2}$ is always flouted in the conflicts between different ideologies, or resulted in various political standpoints. Hence, what seems as defiance in the previous article in Newsweek might have another interpretation and philosophy in Iraq's newspapers. Below is the example which shows the notion of flouting 'quality', and 'manner' maxims of Grice.

IRAQ New Threat
SADDAM HUSSEIN ONCE again laid down a challenge to the United Nations
last Week. On Saturday he announced he was suspending co-operation with U. N arms
inspectors and demanded it purge its team of U. S “Spies and agents'. U. N. officials
say Saddam's defiance comes in response to last week's Security Council decision to
review Iraq's compliance record with guaranteeing when economic sanctions would
be lifted.
(Newsweek, November, 9, 1998)

It has been mentioned that conventional, or rule- based account of natural language usage can never satisfy the needs of the communication process. Thus, the possibility of non-conventional exploitation is considered essential in communication processes.

\footnotetext{
1 Levinson, Stephen. Pragmatics

2 Palmer,F. R. Semantics
} 
TABLE 4

'MANNER' \& 'QUALITY’ MAXIMS AND HEADLINES \& POLITICAL REALITIES

\begin{tabular}{|c|c|}
\hline Propositions & Inferential Mechanism \\
\hline $1 \backslash$ New Threat & $\begin{array}{l}\text { 'Grice's maxim of 'manner' which orders the speaker to avoid obscurity of expression is flouted in } \\
\text { this proposition so that it may be taken to implicate for something. }\end{array}$ \\
\hline $\begin{array}{l}2 \backslash \text { SUDDAM HUSSEIN once } \\
\text { again laid down a challenge to the } \\
\text { United Nations last week ... }\end{array}$ & $\begin{array}{l}\text { Grice's maxim of 'quality' which orders the speaker not say what s/he believes to be false is vi- } \\
\text { olated in order that it may be taken to implicate for something, so what looks as a defiance in this } \\
\text { issue of Newsweek, might have another philosophy and different political stance in Iraqi newspapers. }\end{array}$ \\
\hline
\end{tabular}

The manner maxim of Grice (1975) ${ }^{1}$ which orders the producer of the utterance to avoid obscurity, avoid ambiguity, be brief, and orderly is exploited in the above 'headline', and in headlines in general. That is, headlines usually violate grammatical rules, and are written with special character of vocabularies.

However, the quality maxim can be conceived in that Newsweek issue, reporters normally assert propositional content in which they believe. That is Saddam reaction by suspending cooperation with the UN has been considered as defiance.

\section{CONCLUSION}

Sentence analysis alone (semantics theory) which dominated school classes since 1850 needs other linguistic aspects like pragmatics to complement the issue of meaning. Meaning is a recondite issue which needs pragmatic inferences like implicature to be appropriately understood. Proving the existence of this inference in the language of journalism and the many variations in journalistic styles, this inference can draw a boundary between semantics and pragmatics theories. Many educational syllabuses till now think only of the sentence structure as a source of language learning. Linguistic pragmatic theory has proven its suitability for harnessing the sentence structure to capture the evasive nature of the intended meanings of written or spoken discourses. Implicature as one of the pragmatic inferences can also have an influence on lexicography. That is bilingual dictionaries need strongly the appropriate translatability of implicature since it carries the genuine meaning of the particular utterance and it accounts for all the circumstances surrounding that utterance.

The analysis so far leads us to the importance of this inference in the process of communication. That is, this inference bridges the gap between what is said and what is understood. The traditional grammar has focused on what is said ignoring to a large extent what is understood and this matter dominated language pedagogy for a long time. Linguistics now has developed sentence linguistics by adopting new theories of discourse analysis which caters for what is said and what is intended. Considering the analyses that have been conducted on implicature issue, we understand how this inference is important for glossing the intended meanings behind the different glossary of media writing. This inference has been found in advertisements, reporting the news, headlines, and human interest stories. This means that implicature inference can provide significance for practice and policy to educational agenda of teaching English as a foreign language and to the process of syllabus design . This may change English syllabi to incorporate this notion of implicature when making decisions on the program implementation and the materials to be taught. This inference therefore helps the written articles to appeal to the interests and the attitudes of the intended readers. It also helps these articles to be economical (For example the category of headlines). Journalism always benefits from this inference in its style of variations as well as its causation to the pragmatic cultural transfer of political, economic and social new stories. Eventually, this paper is attempting to support Levinson $(1983)^{2}$ who proposes that assiduous researchers must contribute to prove how far he is right about his claims on pragmatics. The paper also elucidates and expands the linguistic term of implicature by investigating it in live authentic texts.

\section{REFERENCES}

[1] Austin, J. L. 1962; How to Things with words, Oxford: Claremont Press.

[2] Chen,X. and Yuan,Z. Identity Expression in Chinese News Headlines: Social- Psychological Pragmatic Perspective in the Third International Conference on New discourses in Contemporary China, Tianjin , China, 15-16 May.

[3] Cook,G. 1992. The Discourse of Advertising. London. Routlegde.

[4] Cole, P. \& Morgan, J. L.(eds) 1975; Syntax and Semantics 3:Speech Acts. New York: Academic Press.

[5] Duff, B. and R. Swindler 1984; Language and Style In Press, London: Collins ELT.

[6] Fries, C. 1951. The Structure of English. London. Lowe and Brydone. LTD.

[7] Grice, H. P. 1975; Logic and Conversation in Cole, P \& Morgan, J. L (eds) Syntax and Semantics 3: Speech Acts, New York: Academic Press.

[8] Levinson, S. 1983 Pragmatic, Cambridge: Cambridge Univ. Press.

[9] Mueller, C. 1973; The Politics of Communication: A study in the political sociology language, Socialization, and Legitimating. London: Oxford Univ. Press.

[10] Oh, C. K. and Dinneen, D. A. (eds) 1979 Syntax and semantics 11: Presupposition, New York: Academic Press.

\footnotetext{
1 Grice, g. p. Logic and Conversation

${ }^{2}$ Levinson, Stephen. Pragmatics
} 
[11] Palmer, F. R. 1981 Semantics, Cambridge Univ. Press.

[12] Pratt, M. 1977; Toward a Speech Act Theory of Literary Discourse, London: Indian Univ. Press.

[13] Rivers, W. 1964. The Mass Media Reporting , Writing and Editing. New York: Harper and Row.

[14] Searle, J. R. 1969. A speech Acts. Cambridge Univ. Press.

[15] Roksvold, T. 2006. Nordicom Review 27(2006)2PP. 185-204. Web Transcription Tool. http:// www. benjamins.com.

[16] Vivanco, V. 2006. Analyzing Inference and Ethos-Implicature in Particular in GEMA online Journal of Language Studies. Vol 6 (2).PP. !85-204.

[17] Watson, J and Hill, A1997. A dictionary of Communication and media studies. London. Arnold

[18] Weirs, A. 1990. Advertisements in Classroom, English Teaching Forum Vol XXVIII No 2 p.

[19] Xinren, C. and Zhoumin , Y.2009. Third International Conference on New Discourses In Contemporary China, Tianjin, China, 15- 16 May.

[20] Yeh, C. 2004 Language and Linguistics . Vol(3). No2.

[21] Yule, G. 2006. The Study of Language. ( $3^{\text {rd }}$ edn). Cambridge . Cambridge University Press.

Mustafa Shazali Mustafa Ahmed was born in a small town (Abu- Hamad) in northern Sudan in 7/10/1963. He has studied the preliminary, Intermediary and secondary in small town ( Atabra). He got his bachelor degree from Atabra College of Education (English language education) in 1987. He got his M. A (1994) and his Ph. D (2004) from the University of Khartoum in Sudan in English language.

He has been positioned in many academic posts. He has undertaken the responsibility as a Dean of Islamic and Arabic studies for temporary times. A Coordinator and a permanent member in the graduate Council of Nile Valley University in the period (19941999) . Now He is the Head of English Department and a member of the Graduate College/ English Committee. He has some local and International publications. Some of these publications are the following:

- English Language as a Requirement Course for Information Students- in the journal of English Language Teaching vol .2, No. 3, September 2009- Canadian Centre of science and Education.

- Extra Curricular Activities as a Potentially Requirement for a Textbook syllabus- in the Scientific Journal of Alzaiem alazhari University (2009).

- Sudanese Faculties of Education and the Ideology of culture- in the Nile Scientific Journal of Nile Valley University (2005).

Now he is translating many English books. He is writing some papers in Education on the phenomenon of Students Revolts. He is a member in Association of Sudanese Teachers of English. 